\title{
REFERENCE VALUES OF BODY COMPOSITION FOR ADULT FEMALES WHO ARE CLASSIFIED AS NORMAL WEIGHT, OVERWEIGHT OR OBESE ACCORDING TO BODY MASS INDEX
}

\author{
Aliye Ozenoglu, Serdal Ugurlu ${ }^{3}$, Gunay Can ${ }^{1}$, Hüsrev Hatemi ${ }^{2}$ \\ Department of Psychiatry, ${ }^{1}$ Department of Public Health and ${ }^{2}$ Division of Endocrinology, Metabolism and Diabetes \\ and Department of Medicine, Cerrahpasa Medical Faculty, University of Istanbul, Istanbul, Turkey; ${ }^{1}$ Department of \\ Medicine, Medical Faculty, University of Cumhuriyet, Sivas, Turkey
}

\begin{abstract}
Objective. The aim of this study was to establish reference values for body composition as measured by Bioelectrical Impedance Analyser (BIA) in adult females without any endocrinological and/or metabolic disorders, according to their body mass index (BMI) grouped as normal, overweight, obese and morbid obese.

Patients and Methods. This study was performed in a total of 327 adult females. In addition to the estimation of their body weight, height, waist and hip circumference, their body composition was measured by BIA. The results were statistically evaluated by a computer program usig ANOVA test.

Results. Together with the increase of BMI also the percentage of body fat and basal metabolism (BM) increased significantly, while the percentage of body water, fat free mass as well as lean/ fat ratio showed a significant decrease. In addition, waist and hip ratio, percentage of body fat and BM showed a significant positive corelation with BMI.

Conclusion. These results are recommended to be used as reference values for the studies on body composition, especially to predict the degree of body fatness of obese patients and also nutritional status of patients who need nutritional supports.
\end{abstract}

Key Words: Body mass index - Body composition - Bioelectrical impedance analyser - Reference values

Obesity appears an important public health problem defined as the increase of fat tissue in the body which leads to increased morbidity and mortality and shows negative influence on the duration and quality of life. In addition to physiological aspects, it also shows some social and psychological aspects (TuZun 1999; KORUGAN et al.2000). In parallel with the technological advances the ease in obtaining, purchasing and consuming various kinds of food has increased. However, in contrast, physical inactivity, consumption of more cigarettes and alcohol, stress and weakness of the mech- anisms for coping with stress are other environmental factors which make it easier for obesity to develop (BJoRntorP 1993; Siervogel et al. 2000). Nowadays, increasing prevalence of obesity in all age groups of several countries is regarded a disease which must be treated (Korugan et al. 2000). However, in order to define someone as obese, his body weight, body composition and fat distribution in the body should be correctly determined first. It should not be forgotten that, when using only the evaluation of body weight, there are subjects who are accepted to be falsely obese as

Corresponding author: Aliye Özenoglu, PhD., Istanbul University, Cerrahpasa Medical Faculty, Psychiatry Department, 34303 Cerrahpaşa-Istanbul, Turkey, e-mail: serdal.ugurlu@gmail.com; phone: +90 (212) 414 31 30; fax: +90 (212) 4143130 
they have a lot of muscle mass. In addition, there are others who have normal body weight but are accepted to be obese as based on body fat composition and other metabolic parameters (KORUGAN et al. 2000; BROCHU et al. 2000). Thus, it is quite important to diagnose obesity correctly in order to prevent the organic, metabolic, and psychosocial problems it might cause. On the other hand, the measurement of body composition is highly helpful in understanding whether the appropriate individual has a need for any nutritional support.

So far, several methods were developed to detect body composition in humans (ARSLAN 1992; ElLIS 2000). Although direct methods to evaluate body composition do exist, they are not easily applicable in routine clinical practice. So, the applicable methods are indirect. Among them the reliability of bioelectrical impedance analysis (BIA), which was repeatedly confirmed, appears a practical method using the conductivity of the body, namely of the tissues (WAGNER and Heyward 2000; Rosenbaum et al. 2000; CoOper et al. 2000; Pichard et al. 2000; LUKASKI 2000; KyLE et al. 2000). However, since the body composition might vary according to age, sex, ethnic background, nutritional status, exercise, climate, presence of some illnesses and administration of some drugs, it appears important to know the body composition standards for different conditions. However, there are only few reference values available for this purpose (WAGNER and HEYWARD 2000; Pichard et al. 2000; AtKIn and Davies 2000; Kyle et al. 2000). Although reference values of body composition for different age groups obtained by BIA are available in the literature, there are no reference values for body composition of healthy adults matched for age, sex, and body mass index. Although BIA has been used in some studies performed in our country, the number of examined subjects was low and, in addition, the main aim never was to evaluate the effect of the treatment used on the changes of body composition in the investigated group of patients.

Nowadays, it is known that, in the determination of risk factors for various chronical diseases and even for dementia, body fat ratio and fat distribution is more significant than only BMI. Although BMI is widely accepted as a simple marker of adiposity in population-based studies, and is recognised as an instrument to diagnose obesity for all age groups, it should be more properly seen as an index of weight excess, rather than body fatness (CEREDA et al. 2007). The disadvantage of BMI measurement is that it does not provide information on body composition or distinguish between fat and fat free-mass.
For this reason, we aimed to study how the body composition is being changed in relation to BMI in groups of adult women, primarily liviving in Istanbul and to apply the data to the patients of University Hospital in this country. We hope that the results obtained will elucidate the way for the later studies made in this area for different diseases, different treatments or different regions in this area. As a matter of fact, the results of this study which were performed in a large group, could be also beneficial and helpful for the other studies we made so far (Ozenoglu et al. 2000, 2001a,b, 2004 a,b, 2006, $2007 \mathrm{a}, \mathrm{b})$. We suggest to use the results of this study as reference values in similar studies, and also we choose to share this study by publishing to be a countenance for the investigators curious about the changes in the body composition for different conditions, different groups, different diseases and treatments in several countries.

\section{Patients and Methods}

Subjects. The examined group consisted of 327 female subjects were included (all $>18$ years of age) who were admitted to our department between 1999 and 2005 with various complaints evaluated retrospectively. In all subjects the age, sex, climate, nutrition, disease, treatment and other variables known to be effective in body composition were evaluated. The were selected among the adult women who had no history of any known long term disease disease and/or drug use, who lived in Istanbul and applied to our hospital for different reasons. The participants who had not suffer from any endocrine-metabolic, inflammatory, autoimmune, genetic or other long term diseases disorders except of exogenous obesity, were allotted to normal, overweight and obese group according to their BMI. Mean age of subjects was $39.18 \pm 12.02$ years. As a part of the nutritional status assessment, patients height, weight, waist and hip circumference were determined; and the body composition measurement was performed by BIA. BMI was calculated by adjusting the known formula as weight $(\mathrm{kg}) /$ height ${ }^{2}\left(\mathrm{~m}^{2}\right)$.

Examined groups. Subjects with BMI of 18.5-24.9 $\mathrm{kg} / \mathrm{m}^{2}$ were accepted to be normal, those with BMI of $25.0-29.9 \mathrm{~kg} / \mathrm{m}^{2}$ were allotted to overweight, these with BMI of $30.0-39.9 \mathrm{~kg} / \mathrm{m}^{2}$ to obese and those with BMI $340 \mathrm{~kg} / \mathrm{m}^{2}$ to morbid obese group (Tuzun 1999; OzENoGLu 2001a,b; PI Sunyer 1999; DeHoog 1996). Waist/ hip ratio (WHR) was obtained by dividing the waist circumference by the hip circumference.

Body impedance analysis (BIA) depends on the principle that fat is a bad conductor to the applied cur- 
Table 1

Mean values of BMI, waist and hip circumferences, and WHR in females

\begin{tabular}{lcccr}
\hline Degree of obesity & BMI $\left(\mathrm{kg} / \mathrm{m}^{2}\right)$ & Waist $(\mathrm{cm})$ & Hip $(\mathrm{cm})$ & WHR \\
\hline Normal & $21.52 \pm 2.38^{? \beta}$ & $69.41 \pm 15.39^{? \beta}$ & $95.68 \pm 5.44^{? 3}$ & $0.75 \pm 0.050^{? \beta}$ \\
Overweight & $27.18 \pm 1.35^{\mu}$ & $85.77 \pm 6.81^{\mu}$ & $108.58 \pm 4.57^{\mu}$ & $0.79 \pm 0.056^{\mu}$ \\
Obese & $34.37 \pm 2.60$ & $97.06 \pm 14.34$ & $120.13 \pm 10.17$ & $0.81 \pm 0.057$ \\
Morbid obese & $46.88 \pm 6.74$ & $117.47 \pm 11.38$ & $141.37 \pm 19.78$ & $0.83 \pm 0.059$ \\
P & 0.0001 & 0.0001 & 0.0001 & 0.0001 \\
\hline
\end{tabular}

$\alpha=p<0.05$ : normal vs. overweight, $\beta=p<0.05$ : normal vs. morbid obese, $\mu=$ overweight $\mathrm{v}$ morbid obese; $\mathrm{p}$ values mean the trend and are calculated by one way ANOVA followed by Tuikey's test

rent; however, lean body mass is a good conductor depending on its content of water and electrolytes. In order to determine the body impedance, two tetrapolar electrodes are placed on the lateral surfaces of both the right hand and the right foot while the subject is lying down in supine position. There is a low current between the electrodes. Depending on the amplitude of the current, whole body water; or, in low frequencies only extracellular water might be determined (ARSLAN 1992; ELLIS 2000; JEBB 1998). As the method mainly measures body water, the hydration of the subject should be normal. Errors in measurement might occur due to the presence of metals on the bed or the subject, daily variations in body weight and composition due to food intake and exercise, intake of drugs, menstrual cycle in females, and placing the electrodes incorrectly (ELLIS 2000). In this study, optimum care has been taken to minimize errors in measurement and all measurements were performed by the same observer in morning hours. Temperature of the test room was provided to maintain between $18-20^{\circ} \mathrm{C}$. The resistance and reactance values obtained by BIA, together with the age, sex, height and weight of the subject were entered in a computer programme to calculate body water, fat and lean body mass and basal metabolism. Percentage values for body composition, and basal metabolism as kcal. which were obtained automatically by a computer programme, were mainly used in this study. Body fat and lean weight as grams and water as liters were not included in this study. As the body composition of females and males differ, only female subject were taken into this study.

Statistical evaluation. ANOVA test was used in comparing the anthropometric values and body compositions in percentages between groups who were formed according to BMI.

\section{Results}

As shown in Table 1, positive interrelations between the degree of obesity and BMI, waist and hip circumferences as well as waist/hip ratio were increasing highly significantly $(\mathrm{p}<0.0001)$. $\mathrm{s}$ the degree of obesity increases, BMI, waist and hip circumferences also increased significantly. WHR showed a parallel increase with BMI significantly $(\mathrm{p}<0.0001)$. The percentages of body water, fat mass (FM) and lean body mass (LBM), and basal metabolism (BM) obtained by BIA for females are in Table 2.

Table 2

Percentage of body composition and basal metabolism in females according to their BMI groups

\begin{tabular}{|c|c|c|c|c|c|}
\hline Group & Water $(\%)$ & Fat mass $(\%)$ & Lean-body mass $(\%)$ & LBM/ FM & $\mathrm{BM}(\mathrm{kcal})$ \\
\hline Normal & $59.61 \pm 5.01 ?$ ? & $22.78 \pm 4.58 ?$ ? & $77.22 \pm 4.58 ?$ ? & $3.58 \pm 1.16 ?{ }^{? \mathrm{\beta}}$ & $1397.11 \pm 111.10^{? Y \beta}$ \\
\hline Overweight & $52.15 \pm 3.23^{\mu}$ & $29.69 \pm 3.30^{\mu}$ & $70.31 \pm 3.30^{\mu}$ & $2.35 \pm 0.37^{\mu}$ & $1510.44 \pm 119.71^{\mu}$ \\
\hline Obese & $46.10 \pm 3.38^{\llbracket}$ & $35.01 \pm 3.25^{\llbracket}$ & $64.99 \pm 3.25^{\text {II }}$ & $1.87 \pm 0.60^{\mathbb{I I}}$ & $1704.86 \pm 135.24$ \\
\hline Morbid obese & $40.64 \pm 3.44$ & $40.22 \pm 3.60$ & $59.78 \pm 3.60$ & $1.46 \pm 0.23$ & $1978.95 \pm 198.62$ \\
\hline $\mathrm{P}$ & 0.0001 & 0.0001 & 0.0001 & 0.0001 & 0.0001 \\
\hline
\end{tabular}

$\alpha=p<0.05$ : normal vs. overweight, $¥=p<0.05$ : normal vs. obese, $\beta=p<0.05$ : normal vs. morbid obese, $€=p<0.05$ : overweight vs. obese, $\mu=$ overweight vs. morbid obese, $I=p<0.05$ : obese vs morbid obese; $p$ values mean the trend and are calculated by one way ANOVA followed by Tukey's test 
Table 3

Correlations between various measurements in females

\begin{tabular}{|c|c|c|c|c|}
\hline & BMI & Waist circumference & Hip circumference & WHR \\
\hline Waist circumference & $0.814 * * *$ & & & \\
\hline Hip circumference & $0.816 * * *$ & $0.677 * * *$ & & \\
\hline WHR & $0.359 * * *$ & $0.603 * * *$ & $0.213 * *$ & \\
\hline Body water(\%) & $-0.864 * * *$ & $-0.778 * * *$ & $-0.711 * * *$ & $-0.416 * * *$ \\
\hline Fat mass $(\%)$ & $0.858 * * *$ & $0.769 * * *$ & $0.696 * * *$ & $0.418 * * *$ \\
\hline Lean-body mass(\%) & $-0.858 * * *$ & $-0.769 * * *$ & $-0.696 * * *$ & $-0.418 * * *$ \\
\hline LBM/ FM & $-0.681 * * *$ & $-0.575 * * *$ & $-0.548 * * *$ & $-0.248 * *$ \\
\hline BM (kcal) & $0.863 * * *$ & $0.708 * * *$ & $0.755^{* * *}$ & $0.282 * * *$ \\
\hline
\end{tabular}

$* * \mathrm{p}<0.01, * * *$ ise $\mathrm{p}<0.001$

In parallel with the increase in BMI, the percentage of body fat and BM increases; however, the percentages of body water and lean body mass decreases significantly $(\mathrm{p}<0.0001)$.

The correlations of the various measurements made in the study are shown in Table 3.

Highly significant positive correlation was found between BMI and waist and hip circumferences and between the percentage of body fat and BM, whereas a negative correlation was present between BMI and lean body mass, and the percentage of body water. In addition, percentage of body fat had significant correlation with waist and hip circumferences and WHR.

\section{Discussion}

In order to know the nutritional status, it is important to determine the body composition which is varying according to the stages of growth and development, age, sex, ethnicity, genetic and environmental factors, nutritional and exercise habits, various diseases and different therapies (DeHoog 1996; Jевв 1998; Ellis 2000; WAGNER and HeYward 2000). Nowadays, body composition is evaluated at the anatomic, molecular, cellular or tissue-system as well at the whole body level (WANG et al. 1992; Fuller et al. 1992; HeYMSFIELD et al. 1997; DeHoog 1996; Brodie et AL 1998). Since any direct in vivo measurements in humans cannot be performed, the body composition should be determined by indirect methods, while direct measurements might be performed only in cadavers. Among indirect methods used in humans, there are anthropometric measurements, isotope or chemical dilution, body density, conductivity measurements, imaging methods, whole body neutron activation analysis and dual-energy X-ray ab- sorbiometry (DEXA) (WANG et al. 1992; BRODIE et al.1998). Currently, BIA which depends on the conductivity is one of the most preferred methods, since it is easily performed, portable, risk free and also is more economic when compared to other methods and yields reliable results (DeHoog 1996; Jевb 1998; Ellis 2000).

To predict the nutritional status of a patient and to plan his nutritional treatment, it is helpfull to follow the changes in body composition. Determination of the body fat composition appears a particularly important criterion, in understanding the risk not only for obesity and related diseases but also for the development of dementia. BMI, as a readily available measure of weight excess, seems to be a good predictor of both vascular dementia and Alzheimer's Disease (AD) (Kivipelto et al. 2005; Gustafson 2006; Gorospe and Dave 2007), but this measure is limited by the lack of information on body composition and the distribution of body fat. Morover, several factors known to be involved in the development of both vascular dementia and $\mathrm{AD}$, such as hypertension, insulin resistance, pro-inflammatory molecules and atherosclerosis seem more strongly related to body fat distribution, particularly in visceral adipose tissue (VAT) than to the BMI.

Regardless of BMI, patients with increased intraabdominal fat usually show an atherogenic lipid profile, high fasting serum glucose and insulin level and high blood pressure - all metabolic factors participating in the atherosclerotic process. These factors in turn contribute to the occurrence of coronary hearth disease, stroke, as well as peripheral vascular disease (DESPRES and LEMIEUX 2006; SCHNEIDER et al. 2007). Indeed, VAT quantification implies imaging techniques and does not fit in a clinical setting as easily as BMI. However, anthropometric surrogates, such as waist circumference 
(WC), waist to hip and waist to height ratios, and body composition analyses with BIA are more readily available and are routinely used. In our study, highly significant positive correlation was found between BMI and waist and/or hip circumference as well as the percentage of body fat. In addition, percentage of body fat showed a significant correlation with waist and hip circumferences and WHR (Table 3).

In spite of having normal body weight, there might be some subjects with insulin resistance, hypertension, dyslipidemia, and above normal body fat mass (normal weight, metabolically obese) and, on the contrary, it must not be forgotten that some others might be obese in respect of body weight, but their metabolic parameters might be normal which is contrasting to what is being expected (obese, metabolically normal) (Korugan et al. 2000; Brochu et al. 2000). On the other hand, correct determination of the body composition in some patients who need nutritional support for various reasons is of utmost importance. Follow up of the changes in body composition is useful not only for the determination of nutritional status and planning the therapy, but also for the evaluation of the efficiency of administered therapies in such disorders as hormones affecting metabolism, diseases which make it obligatory to use drugs affecting the metabolism, inborn disorders of metabolism in which special diets have vital importance, inflammatory bowel diseases (IBD) which cause deterioration of the patients' nutritional status, chronic renal failure, neurologic disorders, diseases like cancer, the presence of severe disease states or traumas.

Correct determination of the nutritional status in patients with renal failure is important, since it is closely related to the prognosis. In these patients, total body water (TBW), hypertension and cardiac morbidity are accepted to be independant prognostic markers. One study which was planned to assess TBW and nutritional status in end-stage renal failure patients, it was found out that TBW varied greatly depending on the method of calculation (Cooper et al. 2000).

IBD patients are frequently facing malnutrition resulting either from malabsorption or decreased food intake due to gastrointestinal symptoms. Several studies conducted in IBD patients in order to assess their nutritional status revealed that body fat mass was significantly decreased when compared to controls, while the lipid oxidation rate was increased (Capristo et al. 1998, Mingrone et al. 1996, 1999). It was thought that increased lipid oxidation and insufficient energy intake could explain the decrement in fat mass, and it was put forward that enteral diets relatively rich in fat might be useful to sustain the nutritional status of these patients.

Determination of body composition is important for some professions. It is desirable for athletes, artists, ballet-dancers, people occupied in military and legal jobs to keep a certain body fat standard. For instance, Malina et al. (1982) studied the percentage and the distribution of fat of the athletes participating at Olympic Games in Montreal in 1976. They reported that percentage of body fat was affected mostly by physical activity, while the distribution of fat was dependent on biological factors. Ity was found that the distribution of body fat differs between whites and blacks; and that blacks store more fat on the upper part of the trunk when compared to whites (Wagner and Heyward 2000). From these reasons, when determining body composition the age, sex, ethnic background, concurrent diseases and therapies, nutritional habits, activity level, socioeconomic and environmental factors should be carefully investigated.

In order to be able of interpreting body composition measurements, reference values formed under various conditions are needed. However, the number of studies about reference values obtained under various conditions is limited. In this study, we aimed to determine mean body composition values by grouping adult females according to BMI; and, we found out that the body composition changed significantly in accordance with BMI (Table 2). This finding shows that, while interpretting the body composition of one individual, BMI must be taken into consideration.

The first study, in which fat and lean-body mass were determined in healthy subjects according to the sex and age, was performed by PICHARD et al. (2000). In this study, they attempted to determine fat and lean-body mass in different decades by BIA, to detect changes in these values with advancing age, and to develop percentile values for these parameters in a population consisting of healthy whites (1838 males and 1555 females) between 15-64 years of age. It was demonstrated that mean fat mass and percentage of body fat in males increased progressively, while in females such increase occurred after 45 years of age. It was reported that the data in that study could be used as a reference to evaluate whether the body composition of healthy and sick subjects at certain ages was normal.

In another study (Kyle et al. 2000), 25th-75th percentiles of fat and lean-body mass was estimated in 4566 healthy females and males between 20-79 years of age, the subjects being grouped into 20-39, 40-59, 
60-79 age ranges and measurements bing performed with BIA. The authors concluded that the lean body mass decreased and fat mass increased with age. Moreover, these reference percentile values made it possible to interpret the results of BIA and to determine subjects with abnormal muscle and fat mass.

There are different methods to assess the energy needed for basal metabolism. One of these is indirect calorimetry which depends on the measuring oxygen used in biologic oxidations and gives correct and reliable results. However, its use is not widespread because of the difficulties in practice. In daily life, to calculate the energy requirements, methods which can be applied more practically and which depend indirectly on the measurement and calculation are used. In our study, it was found that energy for basal metabolism detected by BIA increased significantly in parallel with the increase in BMI (Table 2).

Barot et al. (1982) compared the measured resting energy expenditure (REE) in 12 IBD patients, nine of them having Crohn's disease, with a calculated formula according to Harris Benedict equation. They found that there was no significant difference between these two values in patients having $>90 \%$ of ideal weight, while those with $<90 \%$ of ideal weight were hypermetabolic when compared to controls. Stokes and Hill (1993) reported that resting metabolic rate detected by measurement in 13 active Crohn's patients was 14 $\%$ higher than that found by calculation.

Recently, we compared BM measured by BIA and calculated by adjusting Harris Benedict equation in female patients with active IBD and women with normal weight according to BMI (OzENOGLU et al 2004), and found that the value obtained by a direct measurement was significantly higher than that obtained by calculation (respectively, $1325.75 \pm 122.92 \mathrm{kcal}$ vs. $1272.82 \pm 102.67 \mathrm{kcal}, \mathrm{p}=0.02)$. In this study in which healthy women matched for age and BMI served as controls, BM in the control group was significantly higher than the calculated value (respectively, $1451.88 \pm 83.5 \mathrm{kcal}$ vs. $1323.27 \pm 74.65 \mathrm{kcal}, \mathrm{p}<0.0001)$.

In another study (Ozenoglu et al. 2001), when comparing BM in healthy adult females and males with normal weight by two different methods, we found that in both sexes BM measured by BIA was significantly higher than that calculated by Harris Benedict formula $(\mathrm{p}<0.0001)$. In a different study (OzENOGLu et al. 2000) we compared BM found by two different methods in females who were either of normal weight, overweight or obese according to BMI, had no endocrine-meta- bolic disorder and no history of any drug usage; the results revealed that BM measured by BIA was significantly higher than that calculated by Harris Benedict equation $(p<0.0001)$. Depending on the results that we obtained in these studies, we concluded that not only in healthy subjects, but also in patients with metabolic diseases, the methods used to determine the body composition and basal metabolism based on direct measurement might be more reliable in predicting energy needs and planning nutritional therapy.

Obesity which is a major health problem in several developing and developed populations, is an independant risk factor for the development of coronary artery disease (CAD). In addition0, obesity increases the risk of CAD by its relation to insulin resistance, hypertenion and dyslipidemia (PI Sunyer 1999; Siervogel et al. 2000; Brochu et al 2000). Determination of body fat is important in defining obesity which might impair quality of life and cause increased morbidity and mortality. Although such techniques as computed tomography (CT) and magnetic resonance (MR) make it possible to evaluate regional body fat distribution and abdominal fat depositions, their use for clinical and epidemiological purposes is limited by their high expenses. The determinants of body fat distribution, like WHR, waist diameter, sagittal diameter, are important alternatives in defining individuals with high risk.

WHR is a simple, useful and sensitive index of body fat distribution. By using this anthropometric index BRAY and GRAY (1998) put forward that WHR $>0.95$ in males and WHR $>0.85$ in females might be useful for the detection of high-risk subjects. Similarly, PAuliot et al. (1994) reported that WHR $>0.85$ in females and WHR $>1.0$ in males might be related to the changes in glucose-insulin homeostasis and lipid-lipoprotein metabolism. It was concluded that waist circumference determined by CT and MR appeared a better indicator of visceral fat than WHR (KoRUGAN et al. 2000; BROCHU et al. 2000). It is accepted that independently of BMI and WHR, a waist circumference $>80 \mathrm{~cm}$ in females and $>94 \mathrm{~cm}$ in males increase the risk for complications of obesity and mortality (ALBERTI et al 2006). Under the light of this knowledge, females in our study who were in obese groups (BMI $>30.0 \mathrm{~kg} / \mathrm{m}^{2}$ ) according to BMI are accepted to have risk for obesity-related diseases (Table 1). As waist circumference and BMI show a very strong relation to the percentage of body fat, while that of WHR is only weak, this confirms that waist circumference is a more sensitive indicator (Table 3). 
It is known that fat tissue forms $20-25 \%$ of body weight in an adult female and $12-15 \%$ of that in a male (De Hoog 1996; Tuzun 1999; PI SunYer 1999). Obesity is accepted to be present when body fat exceeds $30 \%$ in females and $20 \%$ in males. The results of this study are compatible with available literature both for body composition and body circumference measurements.

In conclusion, correct determination of nutritional status of an individual is important for planning therapy under various conditions and for evaluating efficiency of administered therapies. Measurements which depend only on height and weight are usually misleading and insufficient in evaluation of the nutritional status. However, as it is unfeasible to determine body composition in the clinical practice, there is need to develop the standards of methods of indirect measurement.Body composition might show variations according to age, sex, ethnic features, nutritional status, genetic and environmental factors, level of exer- cise, and even the presence of various diseases and administered therapies. For this reason, whenever the body composition of one individual is to be interpreted, it will be useful to use reference values formed under standardized conditions. In addition; whenever there is no possibility of determining the body composition of the individual, the usage of references in order to predict his nutritional status approximately will lead to more reliable results. To achieve this, it is obvious that standardized indirect measurement must be developed for both healthy individuals and stages of the disease. We assume that the results of this study which was the first to evaluate body composition by BIA in groups matched for age, sex, and BMI- might be used as reference values. We also think that diet and exercise programs should be used for the treatment of obesity which is defined as excess fat tissue in the body; and the efficacies of diet and medications should be followed up with measurements of body composition.

\section{References}

Alberti KGMM, Zimmet P, Shaw J: Metabolic Syndrome- a new world-wide definition. A concensus statement from the International Diabetes Federation. Diabetic Medicine 23, 469-480, 2006

Arslan P (editor): Obesity, its influence on various diseases and scientific applications in dietary treatment. 4th Publication of the Turkish Dietetics Association, Ankara, 1992 (Book in Turkish)

ArsLAn P: The calculation of energy and nutrient needs in enteral-parenteral nutrition. In: Enteral-Parenteral Nutrition (Ed. S Basoglu, N Karaagaoglu, N Erbas, A Unlu), pp. 39-49. Publication of the Turkish Dietetics Association, Ankara 1995 (Book in Turkish)

AtKIN LM, DAviES PS: Diet composition and body composition in preschool children. Am J Clin Nutr 72, 15-21, 2000

Barot LR, Rombeau JL, Feurer ID, Mullen JL: Caloric requirements in patients with inflammatory bowel disease. Ann Surg 195, 214-219, 1982

BJORNTORP P: Visceral obesity: a “civilization syndrome”. Obes Res 1, 206-222, 1993

Bray GA, Gray DS: Treatment of obesity. An overview. Diabetes Metab Rev 4, 653-679, 1998

Brochu M, Poehlman ET, Ades PA: Obesity, body fat distribution and coronary artery disease. J Cardiopulm Rehabil 20, 96-108, 2000

Brodie D, Moscrip V, Hutcheon R: Body composition measurements. A review of hydrodensitometry, antropometry and impedance methods. Nutrition 14, 296-300, 1998

Capristo E, Addolorato G, Mingrone G, Greco AV, Gasbarrini G: Effect of disease localization on the anthropometric and metabolic features of Crohn's Disease. Am J Gastroenterol 93, 2411-2419, 1998

Cereda E, Sansone V, Meola G, Malavazos AE: Increased visceral adipose tissue rather than BMI as a risk factor for dementia. Age and Aging 36, 488-491, 2007

Cooper BA, Aslani A, Ryan M, Zhu FY, Ibels LS, Allen BJ, Pollock CA: Comparing different methods of assessing body composition in end stage renal failure. Kidney Int 58, 408-416, 2000

DeHoog S: The assessment of nutritional status. In: Krause's Food, Nutrition and Diet Therapy (Ed. LK Mahan), 9th Ed., pp. 369-374. W.B. Saunders, Philadelphia 1996.

DeSPRES JP, LeMIEUX I: Abdominal obesity and metabolic syndrome. Nature 444, 881- 887, 2006

ELLIS KJ: Human body composition: In vivo methods. Physiological Reviews 80, 649-680, 2000

Fuller N, JebB SA, LASKey M, Cowerd M, Elia M: Four compartment model for the assesment of body composition in humans: Comparision with alternative methods and evaluation of the dansity and hydration of fat free mass. Clinical Science 82, 687-692, 1992 
Gorospe EC, DAve JK: The risk of dementia with increased body mass index: a systematic review. Age Aging 36, 23-29, 2007

Gustafson D: Adiposity indices and dementia. Lancet Neurol 5, 713-720, 2006

Heymsfield SB, Wang ZM, Baumgartner RN, Ross R: Human body composition. Advances in models and methods. Ann Rev Nutr 17, 527-530, 1997

JEBB SA: Measuring body composition: from the laboratory to the clinic. In: Clinical Obesity (Ed. PG Kopelman, M Stock), pp. 18-50, Blackwell Science, Oxford 1998

Kivipelto M, Ngandu T, Fratiglioni L, Viitanen M, Kéreholt I, Winblad B, Helkala El, Tuomilehto J, Soininen H, NISSINEN A: Obesity and vascular risk factors at midlife and the risk of dementia and Alzheimer disease. Arch Neurol 62, 1556-1560, 2005

Korugan U, Damci T, Ozbey N, Ozer E: Clinical Obesity. Publication of the Obesity Working Group, Istanbul, 2000 (Book in Turkish)

Kyle UG, Genton L, Karsegard L, Slosman DO, Pichard C: Validation of a bioelectrical impedance analysis (BIA) equation for the swiss population. Clin Nutr 19 (Suppl 1), S 6, 2000

Kyle UG, Genton L, Karsegard L, Slosman DO, Pichard C: 25-75 th percentiles for fat-free and fat masses in 4566 healthy adults aged 20-79 years determined by BIA. Clin Nutr 19 (Suppl 1), S 6, 2000

LUKASKI HC: Assessing regional mass with segmental measurements of bioelectrical impedance in obese women during weight loss. Ann NY Acad Sci 904, 154-158, 2000

Malina RM, Mueller WH, Bouchard C, Shoup RF, Lariviere G: Fatness and fat patterning among athletes at the Montreal Olympic Games. Med Sci Sports Exerc 14, 445-452, 1982

Mingrone G, Greco AV, Benedetti G, Capristo E, Semeraro R, Zoli G, Gasbarrini G: Increased resting lipid oxidation in Crohn's Disease. Digestive Disease and Science 41 (1), 72-76, 1996

Mingrone G, Capristo E, Greco AV, Benedetti G, De Gaetano A, Tataranni PA, Gasbarrini G: Elevated diet-induced thermogenesis and lipid oxidation rate in Crohn's Disease. Am J Clin Nutr 69 (2), 325-330, 1999

Ozenoglu A, Pamuk GE, Pamuk ON, Sagmanligil SN, Hatemi H: The comparison of basal metabolism found by two different methods amongst females classified as normal, overweight or obese according to body mass index (in Turkish). In: Proceedings of the Third Congress of Clinical Enteral-Parenteral Nutrition, pp. 182, Istanbul 2000

Ozenoglu A: Medical Nutrition Therapy in Obesity (in Turkish). Dilek Ofset, Istanbul, 2001a

Ozenoglu A, Pamuk ON, Pamuk GE, AçBay O, Gundogdu S: The comparison of body compositions and basal metabolism found by two different methods between normal-weight healthy females and males (in Turkish). Trends in Endocrinology 10, 21-24, 2001b

Ozenoglu A, Pamuk GE, Pamuk ON, Hatemi H: The comparison of body composition of women who have inflammatory bowel disease with age, sex, body mass index matched healthy controls (in Turkish). Istanbul Medical Journal 4, 1-5, 2004a

Ozenoglu A, Pamuk GE, Pamuk ON, Hatemi H: The comparison of basal metabolism found by two different methods in normal-weight females with inflammatory bowel disease with healthy controls (in Turkish). Goztepe Medical Journal 19, 15-18, 2004b

Ozenoglu A, Sahin E, Can G, Ugur A, Hatemi H: According to the body mass index, variations at body composition and biochemistry among normal weighted, over weighted and obes women. Science of Diabetes 4, 122-126, 2006

Ozenoglu A, Ugurlu H, Balci H, Eker E: Nutritional approach to metabolic changes arising out of schizophrenia therapy: Case report. J Int Med 46, 1213-1218, 2007a

Ozenoglu A, Ugurlu S, Balci H, Can G, Hatemi H: The effect of a fiber rich dietary product used for the dietary treatment of adult obese women on some biochemical parameters and anthropometric measurements. Romanian Academy Acta Endocrinol III, 315-322, 2007b

PI-SunYer FX. Obesity. In: Modern Nutrition in Health and Disease (Ed. Shils ME, Olson JA, Shike M, Ross AC), 9th ed., pp. 1395-1414, Lippincott Williams \&Wilkins, Philadelphia 1999

Pichard C, Kyle UG, Bracco D, Slosman DO, Morabia A, Schutz Y: Reference values of fat-free and fat masses by bioelectrical impedance analysis in 3393 healthy subjects. Nutrition 16, 245-254, 2000

Pouliot MC, Després JP, Lemieux S, Moorjani S, Bouchard C, Tremblay A, Nadeau A, Lupien PJ: Waist circumference and abdominal sagittal diameter: Best simple anthropometric indexes of abdominal visceral adipose tissue accumulation and related cardiovascular risk in men and women. Am J Cardiol 73, 460-468, 1994 
Rosenbaum K, Wang J, Pierson RN, Kotler DP: Time dependent variation in weight and body composition in healthy adults. Journal of Parenteral and Enteral Nutrition 24 (2), 52-55, 2000

Schneider HJ, Glaesmer H, Klotsche J, Böhler S, Lehnert H, Zeiner AM, März W, Pittrow D, Stalla GK, Wittchen HU: Accuracy of anthropometric indicators of obesity to predict cardiovascular risk. J Clin Endocrinol Metab 92, 589-94, 2007

Siervogel RM, Wisemandle W, Maynard LM, Guo SS, Chumlea WC, Towne B: Lifetime overweight status in relation to serial changes in body composition and risk factors for cardiovascular disease: The feels longitudinal study. Obes Res 8, 422-430, 2000

Stokes MA, Hill GL: Total energy expenditure in patients with Crohn's Disease: Measurement by the combined body scan technique. Journal of Parenteral and Enteral Nutrition 17, 3-7, 1993

Tuzun M: The general features of obesity. In: Obesity and its Treatment (Ed.Yilmaz C), pp. 11-29, Nobel Publication, Izmir 1999 (Book in Turkish)

WAGNER DR, HEYWARD VH: Measures of body composition in blacks and whites: a comparative review. Am J Clin Nutr 71, 1392-1402, 2000

Wang ZM, Pierson RN, Hemsfield SB: The five-level model: a new approach to organising body composition research. Am J Clin Nutr 56, 19-28, 1992 